cases in this group in which surgical interference is advisable. In all probability some of the patients will ultimately recover, whilst it is quite possible that some reports have erred on the side of exaggeration. In others, again, the amount of suffering appears comparatively slight. But on the whole he is inclined to think this group affords some justification for the plea made for more frequent resort to operation in persistent cases of gastric ulcer, always providing the mortality of the operation be kept at a really low figure, and the results are permanently good. At present further evidence on both these points seems to be needed.

$$
1 \text { Lancet, Jan. } 30 .
$$

\section{TRAUMATIC H EMATORRHACHIS.}

Dr. Alexander Miles and Mr. J. C. Carr ${ }^{1}$ report an interesting example of this lesion. The patient, æt. 36, a dock labourer, was heaving a heavy sack over his shoulders when he felt a jerk, as of something giving way "right in between the shoulders." He continued his work for an hour afterwards. During the following night he slept well, but next morning was unable to go to work because of pain and stiffness between the shoulders. When he coughed he had a sensation "like a shock of a galvanic battery" from the place in the back where he was hurt, down the spine and legs to the toes. He walked to the hospital, a distance of half a mile, on the morning of the day following the receipt of the injury. On admission it was observed that he kept his dorsal and cervical spine rigid both on attempting to turn round and to stoop. There was tenderness over the upper two or three dorsal spines, but no irregularity of the spinous processes could be discovered. Soon after admission, his legs became numb and he was unable to move them. He could move his arms with difficulty. Respiration was entirely diaphragmatic. Sensation was entirely lost below the level of the third rib at its junction with the sternum and also partially down the inner sides of the arms. There was retention of urine. On the next day there was considerable distension of the abdomen and breathing was becoming embarrassed. On the following day, the fourth after the accident, operation was decided upon, and laminectomy of the seventh cervical and first dorsal vertebræ performed. A large clot was found between the dura mater and the bone, and on its removal there was considerable bleeding from vessels between the dura mater and the bone in front of the cord. The patient died that evening. At the post-mortem examination it was found that the fifth and sixth cervical vertebræ had been separated from one another. The cord and membranes were intact. There had been no fresh bleeding after the operation.

1 Edin. Med. Jour., Feb. 1904.

\title{
Progress in Bacteriology.
}

Acute Rheumatic Fever.-W. V. Shaw ${ }^{1}$ has conducted a research in order to substantiate the statements of former observers that the diplococcus rheumaticus is capable of exciting a specific fever with the gross anatomical lesions of rheumatic fever. Briefly, our knowledge of the bacteriology of rheumatic fever is as follows :-Klebs, Popow, Netter, and Dana have described a streptococcus. Achalme, Thiroloix, Bettencourt, and Hewlett found an anærobic bacillus. Hiva, Triboulet, Cyon, Apert, and Popoff attribute the disease to a diplococcus which is almost certainly identical with the diplococcus described by Wassermann, Westphal, and Nalkoff, who noted its growth in alkaline media and its tendency to assume a streptococcal form. The existence of such a diplococcus in cases of rheumatic fever has been confirmed by Poynton and Paine, and by Beaton and Ainley Walker. The micrococcus grows on alkaline beef broth, 1 per cent. alkaline peptone agar, glycerine agar, and blood agar. On the last-named it appears in small discrete, colourless, transparent colonies, which gradually coalesce to form a film converting in the second day the red blood into a rusty brown or greenish-brown background. Gelatin is not liquified, neutral milk is coagulated in 48 hours. In broth no turbidity is caused but a flocculent precipitate falls. The cocci measure 5 to $1 \mu$ in diameter and are found in pairs or short chains. In cultures 48 hours old involution forms begin to appear, diplo-baccilli 2.5 to $3 \mu$ long by 5 to $1 \mu$ broad, forming short chains. These resemble the involution forms of the streptococcus scarlatinæ described by Gordon. The micrococcus may be recovered from the blood, urine, tonsils, or joint fluids of cases of rheumatic fever. They are also present in cases of chorea, endocarditis, and in rheumatic nodules. Shaw tested strains of the diplococcus supplied by Wassermann, by Ainley Walker and by Poynton. The differences between these were very small and on rabbits and monkeys they produced when injected intravenously myocarditis, pericarditis, endocarditis, arthritis, pleurisy, iritis. The anatomical nature of these lesions was identical with those found in rheumatic fever. It has been claimed that rheumatic fever is an attenuated pyæmia and that it may be excited by many of the pyogenetic cocci, and it has also been said that vegetative growths on the endocardium are to be found in healthy rabbits. Shaw however believes that the diplococcus of rheumatism is a specific organism, and this would seem to be supported by the fact that it never gives rise to suppuration, and its lesions are of a peculiarly distinctive character. Shaw ${ }^{2}$ says that in none of a large number of rabbits artificially infected with such organisms as B. coli B. typhosus, B. tuberculosis, streptococcus, pneumococcus, etc., and subsequently killed were endocardial changes found so that the power of exciting such changes must be a distinctive quality of the rheumatic diplococcus. These results differ slightly from those recorded by Poynton, ${ }^{3}$ who stated that the maximum growth was obtained anærobically in a medium of milk and bouillon acidified with lactic acid. Poynton laid stress on the fact that the diplococcus perished quickly in the tissues, although leaving behind it lasting changes. $\mathrm{He}$ described, too, a solitary coccal form which 